\title{
COMPARAÇÃO ENTRE CLASSIFICAÇÕES COM REDE NEURAL ARTIFICIAL EM DIFERENTES ÁREAS DE ESTUDO
}

\author{
classifications with artificial neural network in differen study areas \\ Selma Regina Aranha Ribeiro *
}

\begin{abstract}
Resumo
O uso de imagens de satélite para fins de mapeamento é de grande utilidade devido a sua abrangência em termos de área, imageamento em curto intervalo de tempo, análise visual, espectral e baixo custo de aquisição. Com o propósito de classificar digitalmente duas imagens distintas do satélite LandSat TM 5 e 7 este trabalho visa à avaliação da qualidade de classificações digitais em duas áreas diferentes usando Rede Neural Artificial (RNA). Como acurácia das classificações obtidas por meio da RNA foram usadas a Matriz de Confusão e o Coeficiente Kappa. Confirma-se que a RNA é dependente da complexidade da área de estudo, sendo que para cada imagem a ser classificada deverá existir uma arquitetura de rede própria, com amostras puras e representativas das classes definidas na imagem original.
\end{abstract}

Palavras-chave: Imagens orbitais, Classificação digital, Redes neurais artificiais.

\begin{abstract}
The use of satellite images for mapping is very relevant because of its wide coverage in terms of area, imaging in a short period of time, visual analysis, spectral and its low acquisition costs. With the objective of classifying digitally two distinct images from the satellite LandSat TM 5 and 7, this study evaluates the quality of digital classifications in two different areas using Artificial Neural Network (ANN). Confusion Matrix and the Kappa Coefficient were used for accuracy of the classifications obtained by the ANN. It is confirmed that the ANN is dependent on the complexity of the study area and for each image to be classified there should be a network architecture of its own, with pure samples and representative of the classes defined in the original image.
\end{abstract}

Keywords: Satellite images, Digital classification, Artificial Neural Network.

\section{Resumen}

El uso de imágenes satelitales para fines cartográficos son de gran utilidad debido a su alcance de área, imageamento en un corto período de tiempo, el análisis visual, espectral y bajo coste de adquisición. Con el objetivo de clasificar digitalmente dos imágenes distintas del satélite Landsat TM 5 y 7, este estudio tiene como objetivo evaluar la calidad de las clasificaciones digitales en dos áreas diferentes utilizando redes neuronales artificiales (RNA). Como la precisión de las clasificaciones por la RNA se utiliza la Confusión Matriz y el Coeficiente Kappa. Se confirma que la RNA depende de la complejidad del área de estudio y que para cada imagen clasificada debese haver una arquitectura de red propia, con muestras puras y representativas de las clases definidas en la imagen original.

Palabras claves: Imágenes de satélite, Clasificación digital, Redes neuronales artificiales.

(*) Prof ${ }^{\mathrm{a}}$. Dr ${ }^{\mathrm{a}}$ da Universidade Estadual de Ponta Grossa, Departamento de Geociências - Av. General Carlos Cavalcanti, 4748, CEP:84030-900, Ponta Grossa (PR), Brasil Telefone: (+ 55 42) 30203046 - selmar.aranha@gmail.com 


\section{INTRODUÇÃO}

O desenvolvimento de estudos detalhados do uso e cobertura do solo, em qualquer parte da superfície terrestre tem avançado juntamente com as técnicas de sistemas de imageamento remoto.

As imagens orbitais podem ser utilizadas nos mais diversos meios de análise, principalmente nas questões ambientais. Na análise ambiental é imprescindível para o monitoramento de áreas no que diz respeito à cobertura vegetal, níveis de erosão, uso do solo, poluição, disposição irregular de resíduos, ocupação irregular, queimadas, desmatamento, etc.

Com os métodos de classificação e processamento de imagens digitais é possível identificar as áreas críticas afetadas por ação natural ou antrópica, facilitando o planejamento e ações políticas com diretrizes para a gestão destas áreas.

As imagens orbitais podem ser classificadas por meio de um processo de extração de informações, onde são reconhecidos padrões e objetos para fins de mapeamento da superfície terrestre que correspondem a feições de interesse. O resultado obtido da classificação é uma imagem digital constituinte de pixels classificados.

Vários são os métodos para classificar uma imagem orbital, nesta pesquisa foi utilizado o método de classificação por Rede Neural Artificial (RNA) em duas imagens LandSat TM 5 e 7 de diferentes áreas do Paraná, uma correspondente a Represa dos Alagados e outra da Ilha do Mel no litoral paranaense. O método mais usualmente utilizado para classificações é o qualitativo, baseando-se nos elementos da fotointerretação, essa técnica gera resultados subjetivos, pois depende da experiência do interprete. Porém são mais pertinentes técnicas qualitativas de classificação, onde os testes são menos dependentes do intérprete e mais ágeis que a interpretação usual. Nesse contexto o uso da técnica de RNA é adequada no que tange a objetividade e agilidade, acrescentando ainda que a técnica seja parte da inteligência artificial onde procura reproduzir o comportamento humano.

\section{FUNDAMENTAÇÃO TEÓRICA}

O reconhecimento e mapeamento da cobertura existente sobre uma determinada área podem ser realizados por meio de métodos de classificação de imagens digitais. A espacialização e delimitação do espaço físico-territorial são de grande importância para o desenvolvimento do homem, tornam-se fundamentais uma vez que podem subsidiar ações de planejamentos e gestão orientando a forma adequada do uso da terra.

A classificação digital de imagens orbitais permite a extração rápida de informação e definição dos padrões de ocupação da terra. Visa à categorização da cobertura da terra distinguindo as composições de diferentes materiais superficiais.

A identificação e a categorização de pixels em determinadas classes utilizadas no processamento de imagens digitais é denominada de Classificação, essa classificação de dados ocorre com base nas características espectrais de cada pixel da imagem (CENTENO, 2007). O resultado do agrupamento de pixels com características espectrais semelhantes é uma imagem temática, ou seja, o produto final é uma única imagem com poucos valores digitais (LIU, 2006).

São vários os métodos de análise e classificação de imagens digitais, neste trabalho foram utilizadas as técnicas de Inteligência Artificial e o pós-processamento foi gerado por meio da Matriz de Confusão e o coeficiente Kappa para conhecer a confiabilidade da classificação.

A Inteligência Artificial pode ser definida como um conjunto de técnicas de programação que procura resolver problemas em informática, usando algoritmos, que se assemelham ao comportamento humano. (HAYKIN, 1999).

Dentre as linhas de pesquisa da Inteligência Artificial, estão as Redes Neurais Artificiais (RNA), que visam investigar a possibilidade de simulação de comportamentos inteligentes usando modelos baseados no cérebro humano (LIPPMAN, 1987; HILTON, 1989; SIMPSON 1990). 
Segundo Rezende (2003), "a RNA é um modelo matemático que se assemelham às estruturas neurais biológicas e que têm capacidade computacional adquirida por meio do aprendizado e generalização."

O funcionamento de um neurônio biológico pode ser modelado como sendo um circuito binário, o qual possui entradas binárias com valores de 0 a 1, que são combinadas por um soma ponderada, gerando a entrada efetiva do neurônio determinando a continuação desse estímulo (TAFNER et. al, 1995).

As entradas de um neurônio artificial podem ser comparadas exatamente como estímulos do neurônio biológico.

Uma RNA é composta por vários neurônios distribuídos em camadas. A primeira é a camada de entrada e tem a função de armazenar os dados de entrada na rede. As camadas intermediárias são as camadas escondidas, nelas ocorrem os processamentos da rede. A última camada, é definida como camada de saída, recebe os valores processados pela rede (RIBEIRO, 2003).

"A quantidade de neurônios por camadas, o número de camadas por rede e os pesos ajustados após o aprendizado é chamada de arquitetura da rede neural" (ITO, et. al. 2000), representada na figura 01 a seguir.

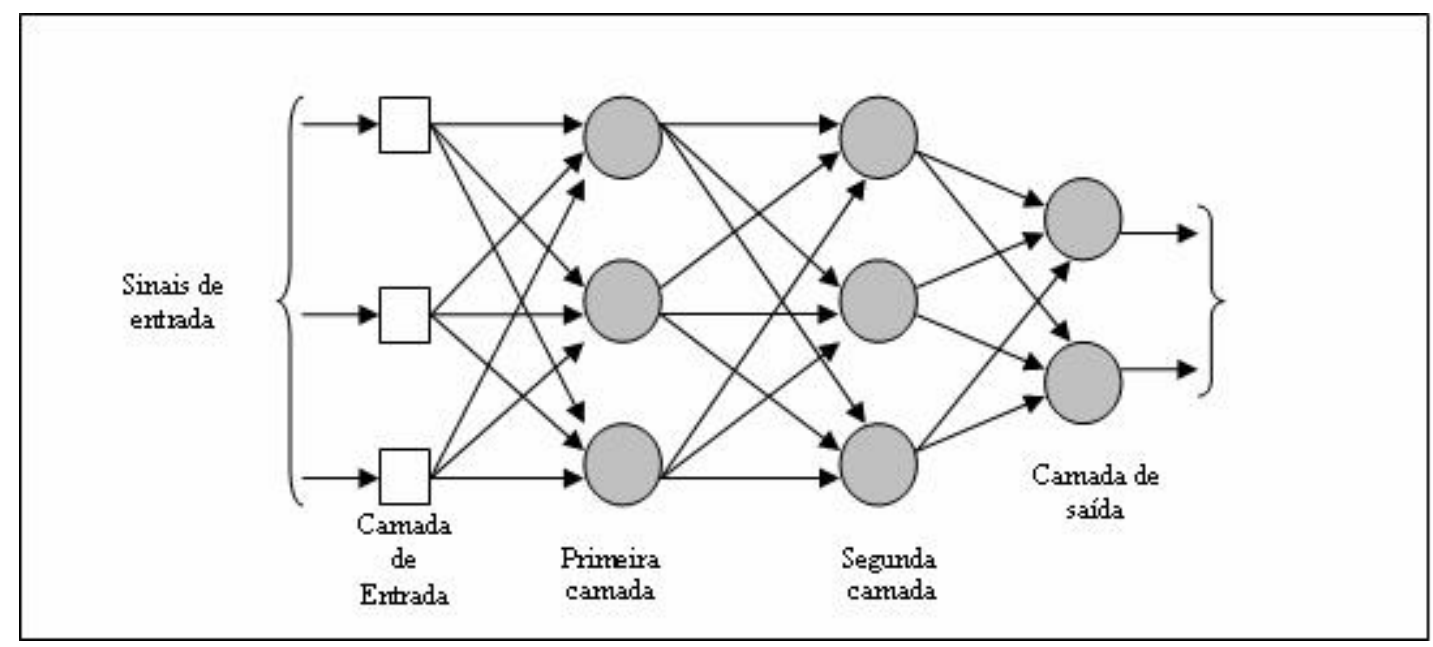

Figura 1 - Arquitetura da Rede Neural Artificial de Haykin, 1999

Segundo LEES (1996), “o método de aprendizagem é uma das partes mais importantes do sistema de RNA e é o que diferencia dos algoritmos convencionais para classificação."

Uma das maiores dificuldades no uso da rede neural é a escolha da melhor arquitetura, para tanto as amostra devem estar distribuídas aleatoriamente na imagem digital que se pretende classificar e devem ser representativas para cada classe determinada (BENEDIKTSSON et. al. 1990).

Após a classificação da imagem digital, é necessário conhecer a confiabilidade e a qualidade da imagem classificada. Uma alternativa consiste em efetuar uma avaliação amostral. As amostras devem ser representativas, seguindo critérios semelhantes àqueles utilizados para amostras de treinamento.

A Matriz de Confusão é uma forma de representar as contradições entre a verdade de campo e o resultado do processo de classificação. Na matriz as linhas correspondem à classe correta e as colunas à classe estimada. Se todos os pixels de uma imagem são classificados corretamente a matriz apresentará valores apenas na diagonal, mas como na maioria dos casos há pixels classificados incorretamente, a quantidade desses pixels incorretos é o total de pixels que aparecem fora da diagonal principal da matriz (ARONOFF, 1982).

Segundo Centeno (2004) “a exatidão de uma classificação também pode ser medida comparando a imagem classificada com um mapa temático resultante de uma classificação completamente 
aleatória." A diferença entre os dois mapas temáticos pode ser medida pelo Coeficiente Kappa, proposto em 1960 por Cohen, onde quanto maior o valor do índice Kappa, o resultado será considerado melhor, sendo 1,0 o valor máximo.

\section{OBJETIVOS}

. Classificar duas imagens LandSat TM 5 e 7 de diferentes regiões com o método de classificação usando RNA;

. Comparar a acurácia dos resultados obtidos na classificação das duas imagens;

. Comparar as arquiteturas da rede utilizadas para a obtenção dos melhores resultados em cada imagem;

. Definir se há um padrão de arquitetura de rede que sempre gere bons resultados em ambas as imagens, ou se é necessário criar uma arquitetura diferente para cada imagem a ser trabalhada.

\section{MATERIAL E MÉTODOS}

Para atingirmos os objetivos propostos pelo presente estudo as duas imagens foram classificadas com o método de RNA, utilizando diferentes amostras de treinamento e diferentes arquiteturas de rede. A seguir serão apresentados os processamentos usados nas imagens para se obter às melhores classificações, que posteriormente serão comparadas entre si.

Foram utilizadas duas imagens LandSat TM 5 e 7, com três bandas do visível, uma do infra-vermelho próximo, uma do infra-vermelho médio e uma do infra-vermelho distante, total de seis bandas espectrais, com resolução espacial de 30 metros obtidas gratuitamente no site (www.inpe. br) do Instituto Nacional de Pesquisas Espaciais, uma referente à Represa dos Alagados em Ponta Grossa - PR (imagem A), adquirida em 4 de junho de 2009, ponto 77 e órbita 221; e outra correspondente à região da Ilha do Mel no litoral paranaense (imagem B), adquirida em setembro de 2002, ponto 78 e órbita 220.

Para realizar a classificação com a RNA foi necessário, para ambas as imagens, coletar amostras de treinamento puras, homogêneas e representativas de cada classe. A coleta e a distribuição espacial de cada amostra foram realizadas com base na análise das imagens (A e B) acima apresentadas e nos mapas topográficos de Ponta Grossa (SG-22-X-C-II-2), Itaiacoca (SG-22-X-C-III-1) e de Abapã (SG-22-E-III-3) para a imagem A e no mapa topográfico de Pontal do Paraná (SG-22-X-D-IV-1) para a imagem B. A amostragem foi realizada com a identificação das áreas de cobertura conhecida na imagem, estas áreas foram demarcadas com o cursor na tela para que o sistema identificasse os pixels que ocupam cada área de acordo com o método exposto por Centeno (2004). Destaca-se ainda que, a validação (índice Kappa e Matriz de Confusão) foi realizada com a coleta de novas amostras de treinamento (pixels) sobre as imagens A e B e que estas novas posições de coletas de amostras de treinamento foram determinadas com visitas "in loco".

A classificação da imagem LandSat 5 TM, recortada na região da Represa dos Alagados em Ponta Grossa - PR, utilizando a RNA como método de classificação, foi realizada com quatro classes distintas baseadas nas cartas topográficas e, presentes na cena da imagem A, de Ponta Grossa (SG22-X-C-II-2), Itaiacoca (SG-22-X-C-III-1) e de Abapã (SG-22-E-III-3) com escalas de 1:50.000, as classes escolhidas foram referentes à água da represa dos Alagados (Água), à vegetação florestal, mata e bosque (Floresta), à vegetação rasteira, arbustiva e campo (Campo) e à cultura temporária, permanente, pomar e vinhedo (Cultura).

Para a imagem da represa dos Alagados foram coletadas ao todo 960 amostras, sendo a amostragem de 240 para cada classe. Foram realizados 40 testes com diferentes arquiteturas de rede, porém com as mesmas amostras de treinamento. 


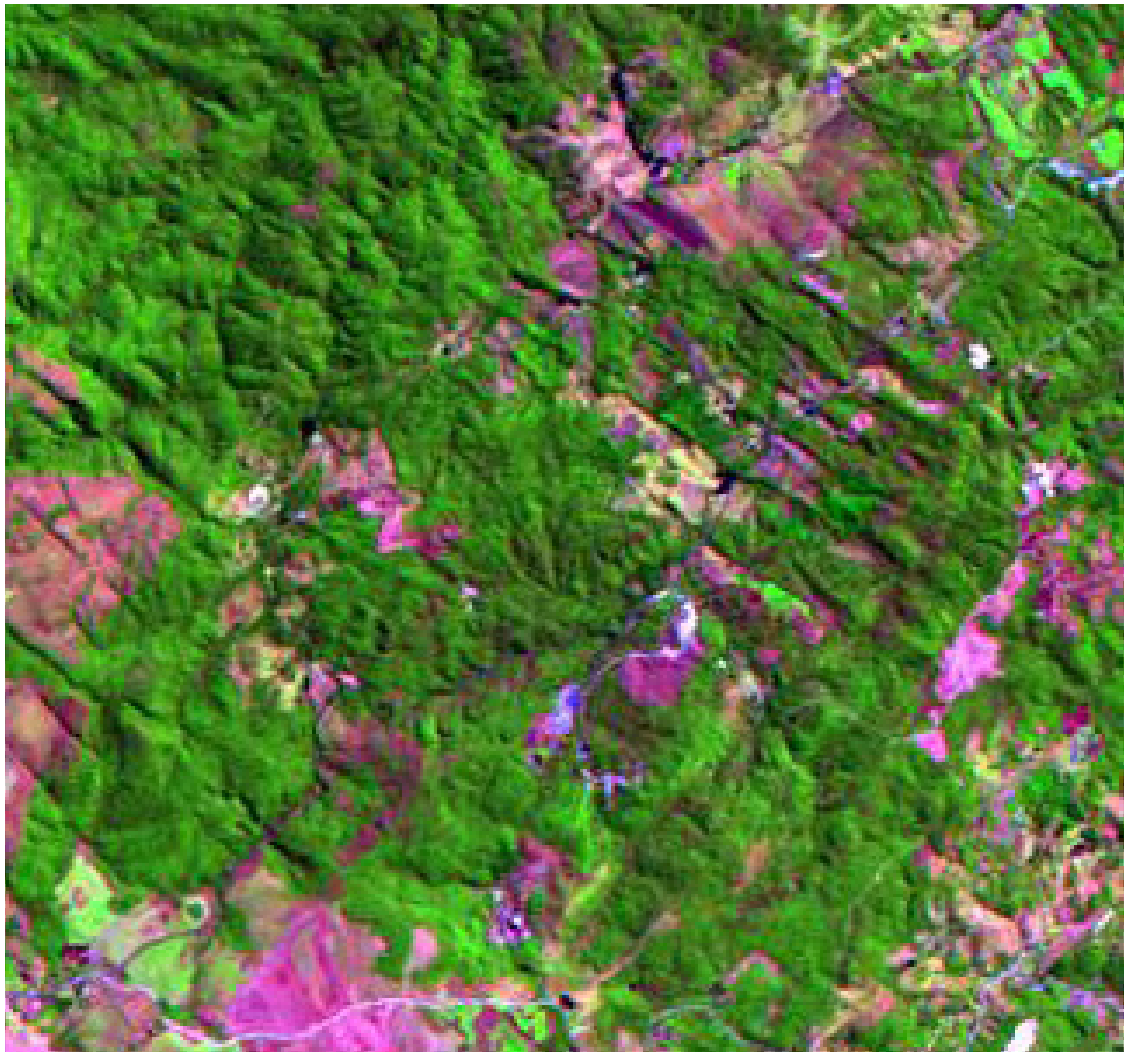

Imagem A - Imagem Landsat 5 TM - Represa dos Alagados - PR. COMPOSIÇÃO COLORIDA FALSA COR 5R 4G 3B

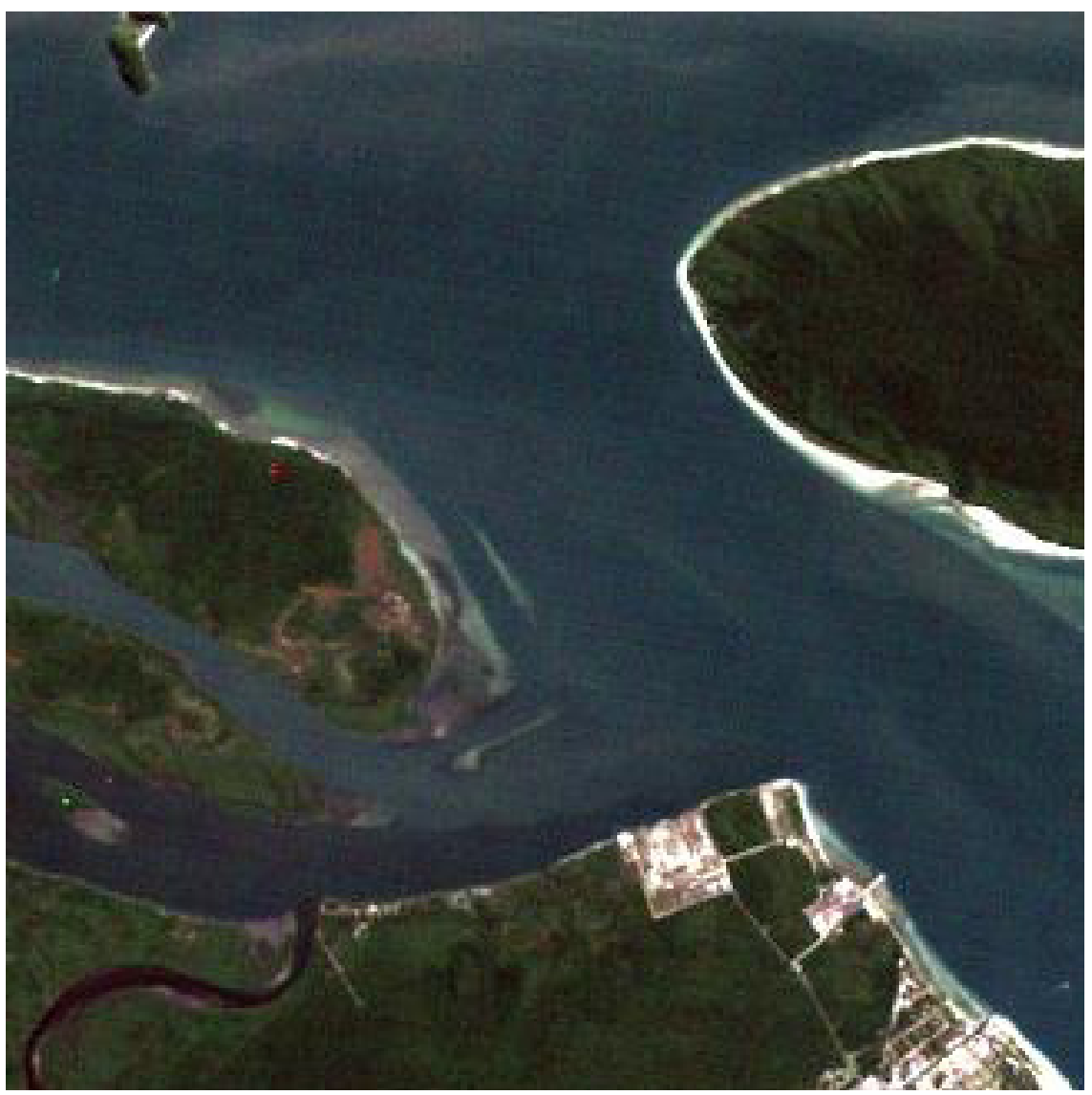

Imagem B - Imagem Landsat $7 \mathrm{TM}$ - Litoral paranaense. COMPOSIÇÃO COLORIDA VERDADEIRA COR 3R 2G 1B 
Após esta etapa foram coletadas 704 novas amostras representativas de cada classe para a aplicação do Coeficiente Kappa e da Matriz de Confusão que avaliam a confiabilidade da imagem classificada. Essa coleta das novas amostras teve como cuidado especial de obtê-las em locais diferentes da primeira amostragem utilizada quando da classificação e com dados originários de visita a campo.

Sendo assim, as 40 classificações obtidas com diferentes parâmetros de arquitetura da RNA passaram pelo cálculo de confiabilidade realizado por meio da Matriz de Confusão e do Coeficiente Kappa.

A classificação da imagem LandSat 7 TM, na região da Ilha do Mel, utilizando a RNA como método de classificação, foi realizada com sete classes distintas baseadas na imagem B; devido a visualização diferenciada das classes, diversas subclasses foram definidas, contemplando mais classes que as apresentadas na carta topográfica de Pontal do Paraná (SG-22-X-D-IV-1), com escala de 1:50.000. As regiões de coleta das amostras foram localizadas em áreas onde as classes são visíveis e existe separabilidade espectral (Índice da Divergência Transformada - DT aproximada de $2,0)$, sendo as amostras puras e representativas de cada classe. Com base na imagem B e complementando as classes do mapa topográfico supracitado as classes escolhidas foram referentes à água de canal, água escura, areia, restinga e solo exposto, vegetação, água com material em suspensão e sombra. Destaca-se que, as classes solo exposto e restinga foram classificadas como uma única classe, embora apresentem resposta espectral diferente (Índice da Divergência Transformada - DT aproximada de 1,9), pois não foi possível coletar amostras distribuídas espacialmente pela imagem para cada um desses alvos. Cabe ressaltar que, apesar da carta topográfica do Pontal do Paraná (SG-22-X-D-IV-1) apresentar uma classe para água, foram definidas três classes para o alvo, porque visualmente é possível diferenciá-las na composição colorida verdadeira cor, como apresentado na imagem B. Para cada classe foram coletadas 50 amostras puras e representativas para gerar a classificação com RNA. Foram realizados 23 testes de diferentes arquiteturas da rede. Na mesma imagem foram coletadas outras 100 amostras para as mesmas classes, porém em diferentes áreas para aplicação do Coeficiente Kappa e a Matriz de Confusão.

Após as duas imagens passarem pelo processamento relatado acima, foram realizadas novas classificações com as mesmas amostras de treinamento, porém com as arquiteturas de rede trocadas, ou seja, as arquiteturas utilizadas para a classificação da imagem da região da Represa dos Alagados foram utilizadas agora para a classificação da imagem da região da Ilha do Mel e vice-versa, com o intuito de verificar a técnica de RNA.

\section{RESULTADOS E DISCUSSÃO}

Com base nos parâmetros de exatidão da Matriz de Confusão e do Coeficiente Kappa foram escolhidas para o presente trabalho os cinco resultados da classificação que obtiveram maior acurácia nas duas imagens LandSat TM 5 e 7.

Na tabela 1 são apresentadas às arquiteturas de cada um dos melhores resultados das melhores imagens classificadas da imagem da represa dos Alagados e seus valores de acurácia.

$\mathrm{Na}$ tabela 2 são apresentadas às arquiteturas dos melhores resultados das melhores imagens classificadas a partir da imagem da região da Ilha do Mel e seus resultados baseados no Coeficiente Kappa e na Matriz de Confusão. 
Tabela 1 - Resultados das classificações da imagem da Represa dos Alagados com redes neurais

\begin{tabular}{cccccc}
\hline & Teste 1 & Teste 2 & Teste 3 & Teste 4 & Teste 5 \\
\hline Training Threshold Contribution & 0,5 & 0,1 & 0,48 & 0,01 & 0,3 \\
\hline Training Rate & 0,5 & 0,1 & 0,48 & 0,01 & 0,4 \\
\hline Training Momentum & 0,9 & 0,2 & 0 & 0,9 & 0,7 \\
\hline Training RMS Exit Criteria & 0,01 & 0,01 & 0,01 & 0,01 & 0,01 \\
\hline Number of hidden layers & 1 & 1 & 1 & 1 & 1 \\
\hline Number of Training Iterations & 2500 & 2500 & 2500 & 2500 & 2500 \\
\hline RMS & 0,01 & 0,03 & 0,01 & 0,03 & 0,01 \\
\hline Coeficiente Kappa & 0,9588 & 0,9545 & 0,9536 & 0,9455 & 0,9427 \\
\hline Matriz de Confusão (Acurácia) & $96,9105 \%$ & $96,5909 \%$ & $96,5199 \%$ & $95,9162 \%$ & $95,7031 \%$ \\
\hline
\end{tabular}

Tabela 2 - Resultados das Classificações da imagem da Ilha do Mel com redes neurais

\begin{tabular}{|c|c|c|c|c|c|}
\hline & Teste 1 & Teste 2 & Teste 3 & Teste 4 & Teste 5 \\
\hline Training Threshold Contribution & 0,1 & 0,32 & 0,7 & 0,54 & 0,5 \\
\hline Training Rate & 0,5 & 0,48 & 0,3 & 0,2 & 0,2 \\
\hline Training Momentum & 0,2 & 0,59 & 0,8 & 0,8 & 0,7 \\
\hline Training RMS Exit Criteria & 0,03 & 0,01 & 0,01 & 0,01 & 0,01 \\
\hline Number of hidden layers & 1 & 1 & 1 & 1 & 1 \\
\hline Number of Training Iterations & 2500 & 2500 & 2500 & 2500 & 2500 \\
\hline RMS & 0,07 & 0,06 & 0,02 & 0,03 & 0,03 \\
\hline Coeficiente Kappa & 0,99 & 0,99 & 0,99 & 0,99 & 0,98 \\
\hline Matriz de Confusão (Acurácia) & $99,8100 \%$ & $99,9600 \%$ & $99,3600 \%$ & $99,2000 \%$ & $99,0400 \%$ \\
\hline
\end{tabular}

Após esta etapa foram realizadas as classificações com as arquiteturas de rede trocadas, onde os parâmetros da rede utilizados na classificação da imagem LandSat 5 TM da região da Represa dos Alagados foram utilizados para a classificação da imagem LandSat 7 TM referente à Ilha do Mel e também ao contrário. A tabela 3 apresenta os cinco melhores resultados da classificação realizada na imagem da Represa dos Alagados obtidos com as arquiteturas utilizadas anteriormente na classificação da imagem LandSat 7 TM da Ilha do Mel no litoral do Paraná.

A tabela 4 mostra as cinco melhores classificações realizadas na imagem da Ilha do Mel utilizando as arquiteturas que anteriormente foram utilizadas para a classificação da imagem LandSat 5 TM da Represa dos Alagados de Ponta Grossa.

Com a análise comparativa entre as duas tabelas referentes aos resultados obtidos a partir da classificação da imagem da Represa dos Alagados (tabelas 1 e 3), podemos observar que a média da acurácia das classificações onde foram utilizadas as primeiras arquiteturas é de $96,3281 \%$ e a média da acurácia obtida na etapa da troca de arquiteturas entre as duas imagens é de $76,8252 \%$. A figura 2 ( 2 a e 2b) mostra a cena da Represa dos Alagados mediante a classificação com RNA tendo a acurácia de 96,9105\% (imagem 2a) e 94,7088\% (imagem 2b). 

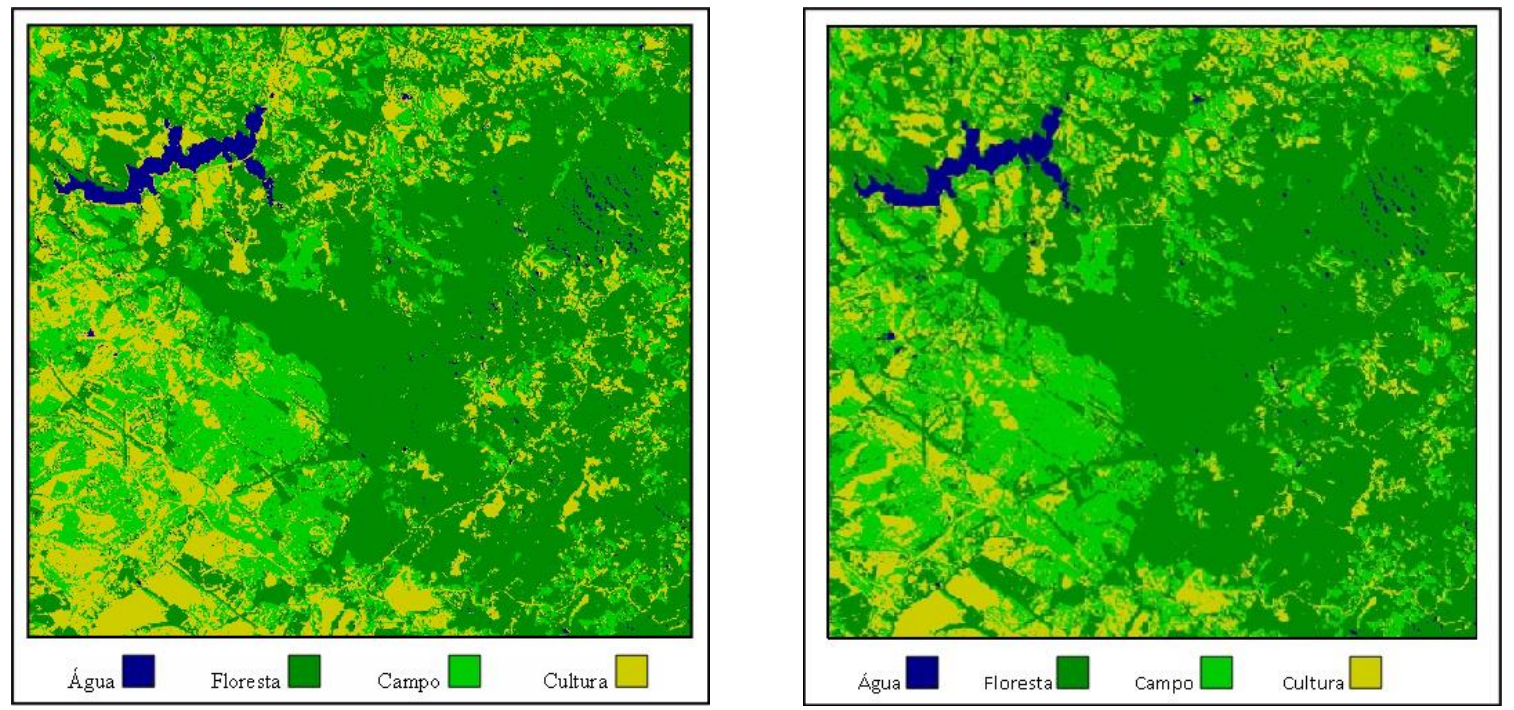

Figura 2 - A: Imagem classificada com acurácia de 96,9105\% (à esquerda);

B: Imagem classificada com acurácia de 94,7088\% (à direita)

Com base nestes dados afirmamos que os melhores resultados são obtidos com as arquiteturas originais utilizadas para classificar a imagem dos Alagados do que utilizando a arquitetura que teve origem na imagem da Ilha do Mel.

Analisando as Tabelas 2 e 4 referentes aos resultados obtidos a partir da imagem da Ilha do Mel, podemos observar que a média da acurácia das classificações realizadas na primeira etapa do processamento com a arquitetura original é de $99,354 \%$ e a média da acurácia das classificações com as arquiteturas originárias da imagem da Represa dos Alagados é de 99,738\%. A figura 3 (3a e 3b) mostra a cena da Ilha do Mel mediante a classificação com RNA tendo a acurácia de 99,81\% (imagem A) e 99,84\% (imagem B).
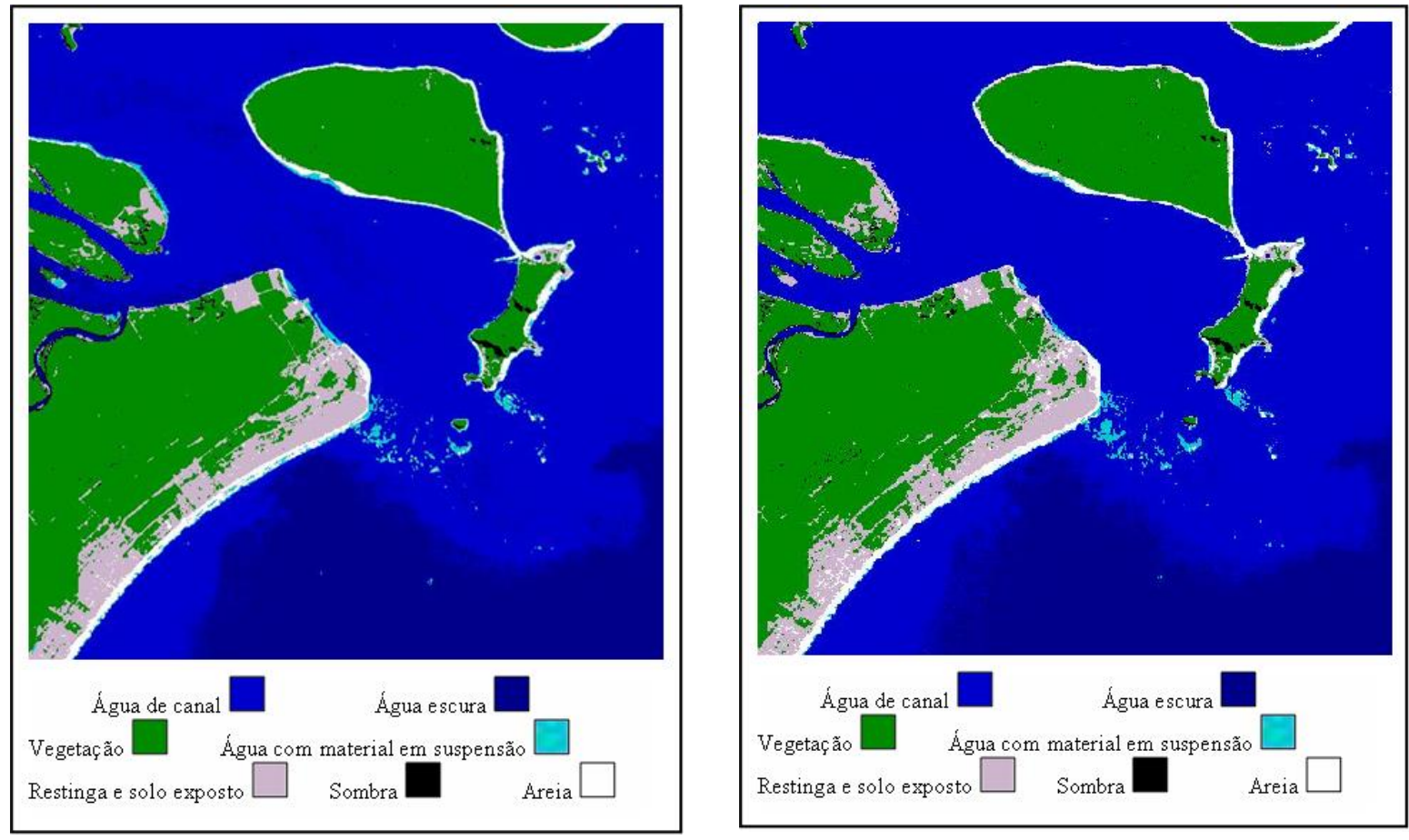

Figura 3 - A: Imagem classificada com acurácia de 99,81\% (à esquerda); B: Imagem classificada com acurácia de 99,84\% (à direita) 
Tabela 3 - Resultados das classificações da imagem da Represa dos Alagados com diferentes arquiteturas de rede

\begin{tabular}{cccccc}
\hline & Teste 1 & Teste 2 & Teste 3 & Teste 4 & Teste 5 \\
\hline Training Threshold Contribution & 0,4 & 0,8 & 0,2 & 0,3 & 0,6 \\
\hline Training Rate & 0,6 & 0,3 & 0,8 & 0,2 & 0,4 \\
\hline Training Momentum & 0,5 & 0,6 & 0,5 & 0,4 & 0,7 \\
\hline Training RMS Exit Criteria & 0,02 & 0,03 & 0,07 & 0,3 & 0,2 \\
\hline Number of hidden layers & 1 & 2 & 1 & 1 & 3 \\
\hline Number of Training Iterations & 2500 & 2500 & 2500 & 2500 & 2500 \\
\hline RMS & 0,02 & 0,23 & 0,06 & 0,3 & 0,35 \\
\hline Coeficiente Kappa & 0,9295 & 0,6477 & 0,6345 & 0,6217 & 0,6217 \\
\hline Matriz de Confusão (Acurácia) & $94,7088 \%$ & $73,5795 \%$ & $72,5852 \%$ & $71,6264 \%$ & $71,6264 \%$ \\
\hline
\end{tabular}

Tabela 4 - Resultados das classificações da imagem da Ilha do Mel com diferentes arquiteturas de rede

\begin{tabular}{c|c|c|c|c|c}
\hline & Teste 1 & Teste 2 & Teste 3 & Teste 4 & Teste 5 \\
\hline $\begin{array}{c}\text { Training Threshold Contribu- } \\
\text { tion }\end{array}$ & 0,5 & 0,48 & 0,2 & 0,7 & 0,1 \\
\hline Training Rate & 0,5 & 0,48 & 0,3 & 0,2 & 0,7 \\
\hline Training Momentum & 0,8 & 0,8 & 0,5 & 0,7 & 0,4 \\
\hline Training RMS Exit Criteria & 0,01 & 0,01 & 0,01 & 0,01 & 0,01 \\
\hline Number of hidden layers & 1 & 1 & 1 & 1 & 1 \\
\hline Number of Training Iterations & 2500 & 2500 & 2500 & 2500 & 2500 \\
\hline RMS & 0,01 & 0,01 & 0,07 & 0,03 & 0,07 \\
\hline Coeficiente Kappa & 0,99 & 0,99 & 0,99 & 0,99 & 0,99 \\
\hline Matriz de Confusão (Acurácia) & $99,8400 \%$ & $99,8400 \%$ & $99,8100 \%$ & $99,6800 \%$ & $99,5200 \%$ \\
\hline
\end{tabular}

Baseando-se nesses dados, observamos nas tabelas 2 e 4, uma melhora de 0,03 nos resultados obtidos com a arquitetura que teve origem no processamento da imagem da Represa dos Alagados, valor esse não relevante numericamente, mostrando um igual desempenho da RNA.

\section{CONSIDERAÇÕES FINAIS}

Com base nos resultados obtidos a partir da classificação de duas imagens LandSat TM 5 e 7 de diferentes regiões podemos concluir que, mesmo obtendo em uma das imagens melhor resultado com as arquiteturas de rede trocadas, não podemos utilizar um padrão de arquitetura para gerar sempre resultados satisfatórios. Os resultados da imagem da Represa dos Alagados mostram que as melhores classificações são geradas a partir de testes de arquitetura sobre a própria imagem e não com a arquitetura criada a partir de testes sobre uma outra imagem. Já os resultados obtidos sobre a imagem da Ilha do Mel mostram que nos 5 testes da rede que foi gerada a partir de outra imagem (Represa dos Alagados), pode gerar resultados mais acurados do que os resultados com a arquitetura original, como apresentado nos resultados e discussão com 99,325\% a média de acertos com a arquitetura original e 99,738\% com a arquitetura da RNA da Represa dos Alagados aplicada a imagem da Ilha do Mel.

Confirma-se que a RNA é dependente da complexidade da área de estudo, pois uma imagem como a da Represa dos Alagados necessita de uma arquitetura de rede treinada para a área de estudo, exigindo mais tempo de treinamento da RNA e um número maior de testes. Já uma imagem como a Ilha do Mel as feições de cada uma das classes são visualmente distintas e, os resultados 
da classificação por RNA usando uma arquitetura de rede definida na própria imagem, assim como uma arquitetura de rede originada de outra imagem geram resultados com percentual semelhante (diferença de 0,384\% entre as médias de acuracidade) quando utilizando outra rede, sugerindo que o comportamento da RNA é semelhante ao de neurônios biológicos quanto à distinção de objetos homogêneos na imagem.

Ressalta-se ainda que, no treinamento da RNA a quantidade de amostras de treinamento para a imagem da represa dos alagados foi o de 200 amostras e para a Ilha do Mel foi de 50 amostras fato que não alterou a classificação.

\section{REFERÊNCIA BIBLIOGRÁFICA}

ARONOFF, S. Clssification accuracy: A USER APPROACH. Photogrammetric Engennering and Remote Sensing. V. 54, 199-214, 1882

BENEDIKTSSON, J. A; SWAIN, P. H; ERSOY, O. K. Neural Network approaches versus statistical methods in classification of multisourse Remote Sensing data. IEEE Transactions on Geoscience and Remote Sensing, v.28, n.4, 1990.

CENTENO, J. A. S. Sensoriamento Remoto e processamento de imagens digitais. Editora: Curso de Pós-Graduação em Ciências Geodésicas, UFPR, Curitiba, 2004.

CEnTEnO, J. A. S. Sensoriamento Remoto: Apostila Módulo Sensoriamento Remoto. Universidade Federal do Paraná, 2007, 42 p.

HAYKIN, S. Neural Networks. A comprehensive foundation. 2 Ed. Prentice Hall. New Jersey, 1999.

HILTON, G. E. Connections leaRNAing procedures. Artificial Intel, v.40, 1989.

ITO, Y; HOSOKAMA, M. LEE, H; LIU, J. G. Extraction of damaged regions using SAR data and neural networks. Amsterdam, IntelRNAational Archives of Photogrammetric Engineering and Remote Sensing, v.33, 2000.

Instituto Nacional de Pesquisas Espaciais - INPE - Acesso em 4 de junho de 2009 e 25 de agosto de 2009 disponível em <www.inpe.br $>$.

LESS, B. G. Neural Network application in the geoscience: an introduction. Computers Geosciences, v.22, n.9, 1996.

LIPPMAN, R. An introduction to computing with neural nets. IEEE ASSP, Magazine, v.2, 1987.

LIU, W. T. H. Aplicações de Sensoriamento Remoto. Campo Grande-MS: Ed. UNIDERP, 2006.

REZENDE, S. O. Sistemas Inteligentes Fundamentos e Aplicações. São Paulo: Editora Manole Ltda. 2003, 525p.

RIBEIRO, S. R. A. Integração de Imagens Landsat TM e dados auxiliares para a delimitação automática de unidades fisionômicas (paisagem) e geológicas usando Redes Neurais Artificiais. Tese apresentada ao curso de Pós-Graduação em ciências Geodésicas da UFPR para obtenção do título de Doutor. Curitiba, 2003.

RICHARDS, J. A. Remote sensing digital image analysis - an introduction. 2nd ed. Springer-Verlag, Berlin. 1993. 281p.

SIMPSON, P. K. Artificial Neural Systems foundations, paradigms, applications and implementations. San Diego: Pergamon Press, 1990.

TAFNER, M. A; XEREZ, M; RODRIGUES, I. W. F. Redes Neurais Artificiais: introdução e princípios de neurocomputação. Blumenau. Editora da FURB, 1995.

Trabalho enviado em março de 2013

Trabalho aceito em abril de 2013 